\title{
Períodos de interferência de maria-pretinha sobre tomateiro industrial
}

\section{Daniel D Hernandez; Pedro Luís CA Alves; Maria do Carmo MD Pavani; Mariana C Parreira}

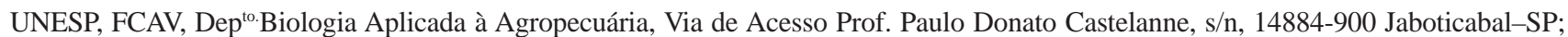
daniel.d.hernandez@bra.dupont.com

\section{RESUMO}

Determinou-se os efeitos da convivência com plantas de mariapretinha sobre a produtividade do tomateiro industrial, híbrido Heinz 9992, em um experimento com dois grupos de tratamentos: no primeiro, o tomate permaneceu livre da competição $\left(60\right.$ mil plantas ha ${ }^{-1}$ de maria-pretinha) do transplantio até $15 ; 30 ; 45 ; 60 ; 75 ; 90 ; 105$ e 120 dias (colheita); no segundo, a cultura permaneceu em competição com a maria-pretinha do transplantio até os mesmos períodos citados. Utilizaram-se blocos casualizados, três repetições e parcelas de quatro linhas. Altura, área foliar e massa seca da parte aérea da maria-pretinha foram obtidas a partir de amostras de dez plantas. A área foliar das plantas de maria-pretinha cresceu até 75 dias de convivência com as plantas de tomate $\left(1.588 \mathrm{dm}^{2}\right.$ planta $\left.^{-1}\right)$, a altura até 60 dias de convivência $(85 \mathrm{~cm})$ e a massa seca da parte aérea até 120 dias de convivência $\left(31,7 \mathrm{~g}\right.$ planta $\left.^{-1}\right)$. As produtividades mais alta $\left(108,6 \mathrm{t} \mathrm{ha}^{-1}\right.$ ou $87,6 \%$ da produção total de frutos) e mais baixa $\left(14,2 \mathrm{t} \mathrm{ha}^{-1} ; 59,0 \%\right)$ de frutos maduros de tomate foram observadas quando a convivência entre tomate e maria-pretinha ocorreu respectivamente apenas nos 15 primeiros dias e ao longo de todo o ciclo do tomate. Nestes tratamentos, o peso médio de frutos maduros foi de respectivamente 58,7 e $38,0 \mathrm{~g}$. Verificou-se que cada $\mathrm{cm}^{2}$ de acréscimo em área foliar das plantas de maria-pretinha causou uma redução de $0,04 \mathrm{t} \mathrm{ha}^{-1}$ na produção de frutos maduros $(\mathrm{PFM})\left(\mathrm{R}^{2}=0,90\right)$, cada centímetro em altura da planta daninha reduziu $0,82 \mathrm{t} \mathrm{ha}^{-1}$ na PFM $\left(R^{2}=0,78\right)$ e cada grama de acréscimo em massa seca de caules e folhas da planta daninha causou uma redução de $2,84 \mathrm{t} \mathrm{ha}^{-1}$ PFM $\left(R^{2}=0,97\right)$. O período anterior à interferência, considerandose a redução na produtividade do tomate em $5 \%$, foi de 27 dias após o transplantio (DAT) da cultura; o período total de prevenção à interferência foi de 46 DAT e, o período crítico de prevenção à interferência, de 27 a 46 DAT.

Palavras-chave: Lycopersicon esculentum, Solanum americanum, competição, coexistência lavoura-planta daninha.

\begin{abstract}
Periods of nightshade interference in processing tomato

In order to evaluate the effects of nightshade coexistence on processing tomato yield, hybrid Heinz 9992, an experiment was carried out consisting of two sets of treatments: in the first set, the crop was kept weed free ( 60 thousands plants $\mathrm{ha}^{-1}$ ) from transplanting to $15 ; 30 ; 45 ; 60 ; 75 ; 90 ; 105$ days and 120 (harvest) days after transplanting (DAT); while in the second set, the crop was kept in competition with the nightshade from transplanting until the same DAT described for the set of treatments. A randomized block design trial, with three replications and four-row plots was used. Height, leaf area, and aerial part dry matter of nightshade was obtained out of 10-plant samples. Nightshade leaf area increased until 75 days of tomato coexistence $\left(1,588 \mathrm{dm}^{2}\right.$ plant $\left.^{-1}\right)$; height until 60 days of coexistence $(85 \mathrm{~cm})$, and the leaf dry biomass until 120 days of coexistence $\left(31.7 \mathrm{~g} \mathrm{plant}^{-1}\right)$. The highest (108.6 tons ha ${ }^{-1}$ or $87.6 \%$ of total production) and lowest (14.2 tons ha $\mathrm{h}^{-1}$ or $59 \%$ ) ripe tomato yields were observed when the coexistence between tomato and nightshade occurred only in the first 15 days or in the whole crop cycle, respectively. In these treatments, the average ripe fruit weights were 58.7 and $38.0 \mathrm{~g}$, respectively. Each $\mathrm{cm}^{2}$ of increase in the nightshade leaf area caused a reduction of 0.04 tons ha-1 $\left(\mathrm{R}^{2}=0.90\right)$ on the ripe tomato yield; each $\mathrm{cm}$ of increase in the nightshade height reduced the ripe tomato yield in 0.82 tons $\mathrm{ha}^{-1}\left(\mathrm{R}^{2}=0.78\right)$; and each gram of increase in the nightshade aerial part dry matter reduced the ripe tomato yield in 2.84 tons $\mathrm{ha}^{-1}\left(\mathrm{R}^{2}=0.97\right)$. The period before interference, allowing up to $5 \%$ reduction in tomato yield, was 27 DAT; the total period for preventing interference was 46 DAT; and the critical period for preventing interference was between 27 and 46 DAT.
\end{abstract}

Keywords: Lycopersicon esculentum, Solanum americanum, weed competition, coexistence crop-weed.

\section{(Recebido para publicação em 16 de novembro de 2005; aceito em 27 de abril de 2007)}

A interferência imposta pelas plantas daninhas é um dos fatores que mais prejudicam a exploração agrícola. As plantas daninhas reduzem a produtividade das lavouras pela ação alelopática e pela competição por fatores de crescimento como água, nutrientes e luz. Além disso, dificultam a colheita e outras práticas culturais, além de serem responsáveis por aumentar os problemas fitossanitários.

Segundo Clark (1971), as espécies de plantas daninhas que se desenvolvem na mesma área da cultura influenciam o grau de competição, pois as habilidades competitivas variam com a espécie. Quanto maior a semelhança fisiológica entre duas espécies, mais intensa é a sua competição pelos fatores que se encontram em quantidades limitadas no ecossistema comum. O grau de interferência das plantas daninhas sobre culturas agrícolas é função de diversos fatores ligados à comunidade infestante $\mathrm{e}$ à cultura, principalmente em decorrência do período de convivência de ambos (Bleasdale, 1960; Blanco, 1972; Pitelli, 1985). De maneira geral, podese dizer que quanto maior for o período de convivência múltipla entre a lavoura e a comunidade infestante, maior será o grau de interferência. No entanto, o grau de interferência dependerá sobremaneira da época do ciclo da cultura em que este período ocorrer (Pitelli, 1985).

O tomate é uma cultura de importância mundial, com o Brasil se destacando como um dos maiores produtores desta hortaliça, quando se trata de produção destinada à indústria, com aproximadamente 17 mil ha plantados em 2004 e uma produção de cerca de 1.500.000 toneladas, ou seja, uma produtividade de $85 \mathrm{t} \mathrm{ha}^{-1}$ (Agrianual, 2005). No entanto, as informações so- 
bre a interferência de plantas daninhas sobre a cultura são escassas. No caso do tomate rasteiro, destinado prioritariamente à indústria, a maria-pretinha (Solanum americanum) destacase como uma planta daninha altamente prejudicial à cultura. Hernandez et al. (2002), ao estudarem o efeito da densidade em monocultura e proporção de plantas de tomate industrial e de mariapretinha em competição, observaram que a planta daninha mostrou ser um competidor muito agressivo e que, à medida que se aumentava a densidade da planta daninha, maiores foram as perdas de produtividade do tomateiro.

Este trabalho foi desenvolvido com o objetivo de determinar o período anterior à interferência (PAI), o período total de prevenção da interferência (PTPI) e o período crítico para prevenção da interferência (PCPI) de mariapretinha sobre o tomateiro, com vistas ao estabelecimento de um programa de manejo desta importante planta daninha na cultura do tomate para indústria.

\section{MATERIAL E MÉTODOS}

O experimento foi instalado e conduzido na Estação Experimental da Unilever Bestfoods, Goiânia (GO). No preparo do solo, antes do transplantio das mudas de tomate e maria-pretinha, foi realizada calagem com a incorporação de $4 \mathrm{t} \mathrm{ha}^{-1}$ de calcário dolomítico, fosfatagem com $550 \mathrm{~kg} \mathrm{ha}^{-1}$ de Yoorin Master (S) e $475 \mathrm{~kg} \mathrm{ha}^{-1}$ de cloreto de potássio. A adubação de plantio foi realizada com o uso de $1,5 \mathrm{t} \mathrm{ha}^{-1}$ da fórmula 4-30-16, além da adubação de cobertura com $280 \mathrm{~kg} \mathrm{ha}^{-1}$ da fórmula 18-027, 21 dias após o transplantio das mudas. O transplantio da mudas de tomate, cultivar Heinz 9992, se deu em 27/ $05 / 03$, no espaçamento de $1,30 \mathrm{~m}$ nas entrelinhas e $0,25 \mathrm{~m}$ entre plantas, resultando em uma população de aproximadamente 30 mil plantas ha ${ }^{-1}$.

Com o intuito de estabelecer os períodos críticos de interferência da mariapretinha sobre o tomateiro sem a presença de outras espécies de plantas daninhas que pudessem comprometer os resultados, realizou-se em prétransplantio das mudas de tomate a aplicação dos herbicidas trifluralina e metribuzin, nas doses de $1200 \mathrm{~g}$ ia ha-1 e $480 \mathrm{~g}_{\text {ia ha }}{ }^{-1}$, respectivamente.

Os tratamentos experimentais foram divididos em dois grupos. No primeiro, o tomate permaneceu livre da interferência da maria-pretinha desde o plantio das mudas até diferentes períodos do seu ciclo de desenvolvimento: 0-15, 030, 0-45, 0-60, 0-75, 0-90, 0-105 0-120 dias após o transplantio (colheita). Após estes períodos, as mudas de maria-pretinha foram plantadas aleatoriamente nas parcelas, em densidade equivalente a 60.000 plantas ha ${ }^{-1}$, deixando-as crescer livremente. A densidade populacional de infestação de mariapretinha foi determinada previamente por meio de amostragens realizadas em lavouras comerciais de tomate na região de Patos de Minas, MG, seguindo o procedimento proposto por Matteucci \& Colma (1982). No segundo grupo de tratamentos, procedeu-se ao contrário. A cultura permaneceu sob interferência da população de maria-pretinha desde o plantio das mudas até diferentes estádios do desenvolvimento $(0 ; 30 ; 45 ; 60$; 75; 90; 105 e 120 dias). Após estes períodos, as plantas de maria-pretinha foram removidas das parcelas com capina manual, o mesmo ocorrendo com outras plantas daninhas que vieram a germinar durante o ciclo da cultura. As mudas de maria-pretinha e de tomate foram produzidas em bandejas de poliestireno expandido de 288 células.

Foi adotado o delineamento experimental em blocos casualizados, com três repetições. As parcelas experimentais foram compostas por quatro linhas de plantio de tomate espaçadas em 1,30 metros, com cinco metros de comprimento, totalizando $26 \mathrm{~m}^{2}$, deixando as duas linhas laterais como bordaduras. As avaliações foram realizadas nas duas linhas centrais de cada parcela, o que representou uma área útil de $13 \mathrm{~m}^{2}$.

Nas parcelas destinadas à convivência inicial da cultura com a comunidade infestante (tratamentos no mato), as amostragens das plantas de maria-pretinha foram realizadas ao final do período estipulado. Para estas amostragens foram coletadas dez plantas de mariapretinha por área útil de cada parcela. Destas plantas, foram obtidas as alturas, áreas foliares (Li-Cor, mod. LI 2000
A) e massa seca da parte aérea e, em seguida, suas respectivas médias.

A lavoura foi colhida manualmente 120 dias após o transplantio, sendo sua produtividade quantificada e extrapolada para toneladas por hectare. Obteve-se as produtividades de frutos maduros, frutos coloridos, frutos verdes e frutos podres, perfazendo quatro características a serem consideradas separadamente. Foram ainda separadas amostras de 50 frutos maduros por parcela para a obtenção do peso médio por fruto. Os dados referentes à altura, área foliar e massas secas acumuladas de folhas e caules das plantas de maria-pretinha, juntamente com os dados de produtividade do tomateiro, foram submetidos à análise de regressão pelo modelo sigmoidal de Boltzman e obedecem à equação a seguir, sugerida por Kuva et al. (2001):

$$
Y=\frac{\left(A_{1}-A_{2}\right)}{1+e^{(x-x 0) / d x}}+A_{2}, \text { em que: }
$$

$\mathrm{Y}=$ produção de tomate em função dos períodos de controle ou de convivência; $\mathrm{x}=$ limite superior do período de controle ou convivência; $A_{1}=$ produção máxima obtida nas parcelas mantidas no limpo durante todo o ciclo; $\mathrm{A}_{2}=$ produção mínima obtida nas parcelas mantidas com competição durante todo o ciclo; $\left(\mathrm{A}_{1}-\mathrm{A}_{2}\right)=$ perda de produção; $x_{0}=$ limite superior do período de controle ou de convivência, que corresponde ao valor intermediário entre a produção máxima e mínima; $\mathrm{dx}=$ parâmetro que indica a velocidade de perda ou ganho de produção (tangente a no ponto $\mathrm{x}_{0}$ ). Foram ainda estabelecidas correlações entre as características analisadas das plantas de maria-pretinha e a produção de frutos maduros de tomate.

\section{RESULTADOS E DISCUSSÃO}

A área foliar das plantas de mariapretinha (Figura 1A) foi crescente até 75 dias de convivência com as plantas de tomate, quando se estabilizou em torno de $1.588 \mathrm{dm}^{2}$ planta $^{-1}$. O crescimento em altura ocorreu até 60 dias de convivência, quando atingiu o ponto máximo, $85 \mathrm{~cm}$ (Figura 1B). Para a produ- 
ção de massa seca da parte aérea das plantas de maria-pretinha (Figura 1C), observou-se um acúmulo com o aumento do período de convivência, atingindo o máximo com 120 dias de convivência (31,7 g planta $\left.^{-1}\right)$. Resultado semelhante foi obtido por Salgado et al. (2002). Neste trabalho, a massa seca da parte aérea de plantas de uma comunidade infestante da cultura do algodão também aumentou até a obtenção da máxima acumulada 120 dias após a semeadura. Kozlowski et al. (2002) estudaram o efeito de plantas daninhas sobre a cultura do feijoeiro e também observaram aumento de massa seca da parte aérea das plantas infestantes com o aumento do período de convivência com a cultura.

Observou-se que o aumento do período de convivência com a planta daninha diminuiu progressivamente a produção de frutos maduros do tomateiro (Figura 2A). A maior produtividade de frutos maduros foi observada no tratamento em que a convivência entre tomate e maria-pretinha ocorreu apenas nos 15 primeiros dias do ciclo $(108,6 \mathrm{t}$ ha $^{-1}$ ou $87,6 \%$ da produção total de frutos). A menor produtividade também de frutos maduros foi observada no tratamento cuja presença da maria-pretinha se deu ao longo de todo o ciclo do tomate $\left(14,2 \mathrm{t} \mathrm{ha}^{-1}\right.$ ou $59,0 \%$ da produção total de frutos), o que representa uma redução de quase $87 \%$ em relação ao tratamento com melhor produção. $\mathrm{O}$ peso unitário de frutos maduros do tomateiro também diminuiu progressivamente com o aumento do período de convivência entre a cultura e a planta daninha (Figura 2B). Ao se comparar o peso unitário de frutos de plantas de tomate que estiveram em convivência com plantas de maria-pretinha apenas nos primeiros 15 dias de seu ciclo ao peso unitário de frutos de plantas que estiveram nesta convivência por todo o seu ciclo, nota-se uma diminuição de $35 \%$ (58,7 gramas contra 38,0 gramas, respectivamente), indicando que a redução na produtividade do tomateiro também foi uma consequência direta da diminuição no tamanho dos frutos. Soares et al. (2003), estudando a interferência das plantas daninhas em cebola, também verificaram que o aumento do período de convivência entre plantas daninhas e cultura resultou em redução na produti-
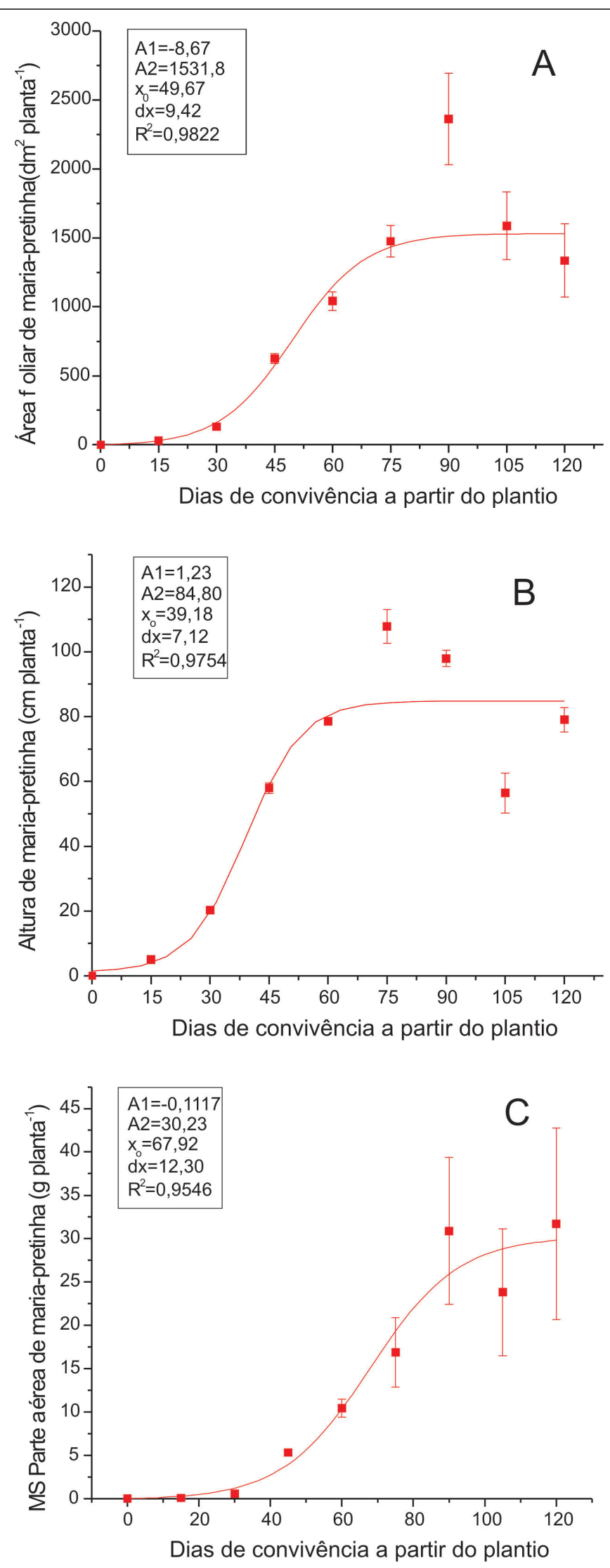

Figura 1. Área foliar $\left(\mathrm{dm}^{2}\right)(\mathbf{A})$, altura $(\mathrm{cm})(\mathbf{B})$ e massa seca da parte aérea por planta $(\mathrm{g})$ (C) de maria-pretinha ao final dos períodos de convivência com o tomate (Leaf area $\left(\mathrm{dm}^{2}\right)$ (A), height $(\mathrm{cm})(\mathbf{B})$, and aboveground plant dry matter $(\mathbf{C})$ of nightshade in the end of the coexistence period with tomato). Goiânia, UNESP-FCAV/Unilever, 2003. 

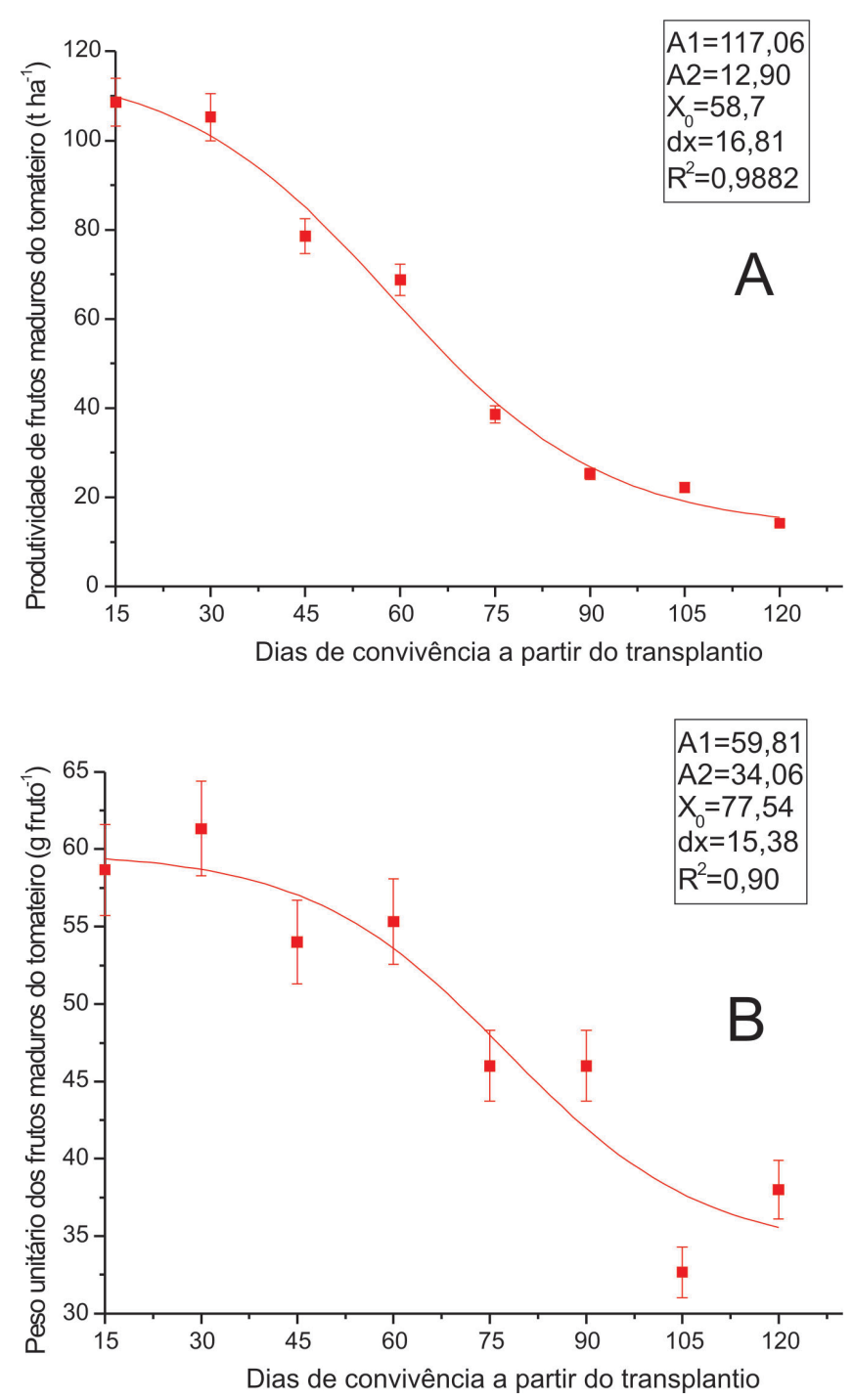

Figura 2. Produtividade $\left(\mathrm{t} \mathrm{ha}^{-1}\right)(\mathbf{A})$ e peso unitário $\left(\mathrm{g} \mathrm{fruto}^{-1}\right)(\mathbf{B})$ de frutos maduros de tomate ao final dos períodos de convivência com a maria-pretinha (Yield $\left(\mathrm{t} \mathrm{ha}^{-1}\right)(\mathbf{A})$ and fruit weight $\left(\mathrm{g}_{\text {fruto }}{ }^{-1}\right)(\mathbf{B})$ of ripe tomato fruits in the end of the coexistence period with nightshade). Goiânia, UNESP-FCAV/Unilever, 2003.

Tabela 1. Produtividade total e de frutos coloridos, verdes e podres do tomateiro e respectivas porcentagens em relação à produtividade total em função de diferentes períodos de convivência com plantas de maria-pretinha (Total and discolored, green, and rotted tomato fruit yield and respective percentage in relation to total yield as influenced by the coexistence period with nightshade). Goiânia, UNESP-FCAV/Unilever, 2003.

\begin{tabular}{lccccccc}
\hline \multirow{2}{*}{$\begin{array}{l}\text { Dias de } \\
\text { convivência }\end{array}$} & \multicolumn{7}{c}{ Produtividade (t ha-1) e porcentagem de frutos em cada classe } \\
\cline { 2 - 7 } & \multicolumn{2}{c}{ Total } & \multicolumn{2}{c}{ Coloridos } & \multicolumn{2}{c}{ Verdes } & \multicolumn{2}{c}{ Podres } \\
\hline 15 & 123,9 & 5,4 & 4,3 & 6,0 & 4,8 & 3,9 & 3,2 \\
30 & 124,4 & 7,9 & 6,4 & 5,6 & 4,5 & 5,6 & 4,5 \\
45 & 93,5 & 5,8 & 6,2 & 5,4 & 5,8 & 3,8 & 4,0 \\
60 & 85,0 & 5,5 & 6,5 & 7,1 & 8,4 & 3,6 & 4,2 \\
75 & 57,5 & 2,7 & 4,7 & 12,9 & 22,4 & 3,2 & 5,7 \\
90 & 34,6 & 2,4 & 6,9 & 2,4 & 6,9 & 4,5 & 13,1 \\
105 & 33,1 & 3,7 & 11,1 & 2,1 & 6,3 & 5,1 & 15,5 \\
120 & 24,0 & 2,5 & 10,4 & 2,2 & 9,0 & 5,1 & 21,4 \\
\hline
\end{tabular}

vidade e no peso médio de bulbos (95 e $91 \%$, respectivamente).

Para a produção total de frutos coloridos também observou-se melhor produtividade para as plantas de tomate nos tratamentos em que a presença da maria-pretinha ocorreu por um período mais curto (Tabela 1). Verificou-se atraso na maturação de frutos com o aumento do tempo de convivência entre o tomate e a maria-pretinha, conforme observado nos tratamentos em que o tomate a maria-pretinha conviveram por 105 e 120 dias. Nestes tratamentos têmse uma porcentagem de frutos coloridos maior do que nos demais tratamentos, $11,1 \%$ e 10,4\% em relação à produção total de frutos, respectivamente. Verificou-se que as plantas do tratamento em que a maria-pretinha e o tomate conviveram nos primeiros 75 dias produziram uma grande quantidade de frutos verdes $(22,4 \%$ da produção total de frutos deste tratamento). Tal fato pode ser explicado por ser neste período que ocorre o máximo de florescimento da planta de tomate. Ao se eliminar as plantas de maria-pretinha, a cultura, que possuía grande poder fisiológico para o florescimento neste estádio fenológico, restabeleceu um novo florescimento, o que propiciou uma nova produção de frutos, totalmente desigualados em maturação com os demais tratamentos.

O aumento do período de convivência entre o tomate e a maria-pretinha provocou também um aumento na quantidade de frutos podres (Tabela 1). Nos tratamentos em que o tomate e a mariapretinha conviveram por 90, 105 e 120 dias do ciclo do tomateiro, 13,1, 15,5 e $21,4 \%$ da produção total de frutos eram, respectivamente, frutos deteriorados. Para a indústria, a qualificação dos frutos colhidos e enviados ao processamento fabril é priorizada, com frutos verdes e podres sendo totalmente descartados. Com isso, verifica-se a importância do controle das plantas de maria-pretinha no momento adequado no ciclo do tomateiro, o que, se não ocorrer, poderá ocasionar aumentos consideráveis da quantidade desses frutos indesejáveis.

Pelos estudos de correlação entre as características analisadas nas plantas de maria-pretinha e a produção de frutos 
maduros do tomateiro $(\mathrm{P})$, verificou-se que cada $\mathrm{cm}^{2}$ de acréscimo em área foliar das plantas de maria-pretinha (AF), em uma população de 60 mil plantas ha- ${ }^{-1}$, causou uma redução de $0,04 \mathrm{t} \mathrm{ha}^{-1}$ na produção máxima de $103,9 \mathrm{t} \mathrm{ha}^{-1}$ de frutos maduros de tomate $(\mathrm{P}=103,9$ 0,04AF; $\left.\mathrm{R}^{2}=0,90\right)$. Na correlação entre altura das plantas de maria-pretinha (Alt) e produção de frutos maduros do tomateiro $(\mathrm{P})$, cada centímetro em altura da planta daninSha, na população de 60 mil plantas ha-1, reduziu $0,82 \mathrm{t} \mathrm{ha}^{-1}$ na produção máxima de $109,3 \mathrm{t} \mathrm{ha}^{-1} \mathrm{de}$ frutos maduros de tomate $(\mathrm{P}=109,3$ $\left.0,82 \mathrm{Alt} ; \mathrm{R}^{2}=0,78\right)$. Verificou-se ainda que, na correlação entre massa seca da parte aérea das plantas de maria-pretinha (MS) e a produção de frutos maduros do tomateiro $(\mathrm{P})$, cada grama de acréscimo em massa seca de caules e folhas da planta daninha, em uma po-

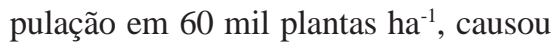
uma redução de $2,84 \mathrm{t} \mathrm{ha}^{-1}$ na produção máxima de 100,2 $\mathrm{t} \mathrm{ha}^{-1}$ de frutos maduros de tomate $\left(\mathrm{P}=100,2-2,84 \mathrm{MS} ; \mathrm{R}^{2}\right.$ $=0,97)$. Entre os três coeficientes de correlação, aquele relativo à massa seca da parte aérea da maria-pretinha, por ser maior, indicou ser esta a característica que melhor expressa o efeito da mariapretinha e sobre a produtividade do tomate. Portanto, em uma avaliação visual, seria mais seguro determinar os efeitos prejudiciais da presença das plantas de maria-pretinha sobre o tomateiro pelo volume de caules e folhas da planta daninha do que simplesmente avaliar sua altura. Além disso, os coeficientes angulares obtidos nos estudos de correlação demonstraram ser a massa seca da parte aérea das plantas de mariapretinha a característica que reduziu de forma mais acentuada a produtividade do tomateiro.

Admitindo perda máxima de 5\% em relação à produtividade obtida na ausência total de plantas daninhas, pôde-se observar (Figura 3; Tabela 2) que a produtividade de frutos maduros do tomateiro passou a ser afetada negativamente a partir de 27 dias de convivência (período anterior à interferência - PAI) (Figura 3). Por outro lado, foi necessário o controle das plantas de maria-pretinha por 46 dias para que a produção atingisse $95 \%$ da produtividade máxima (pe-

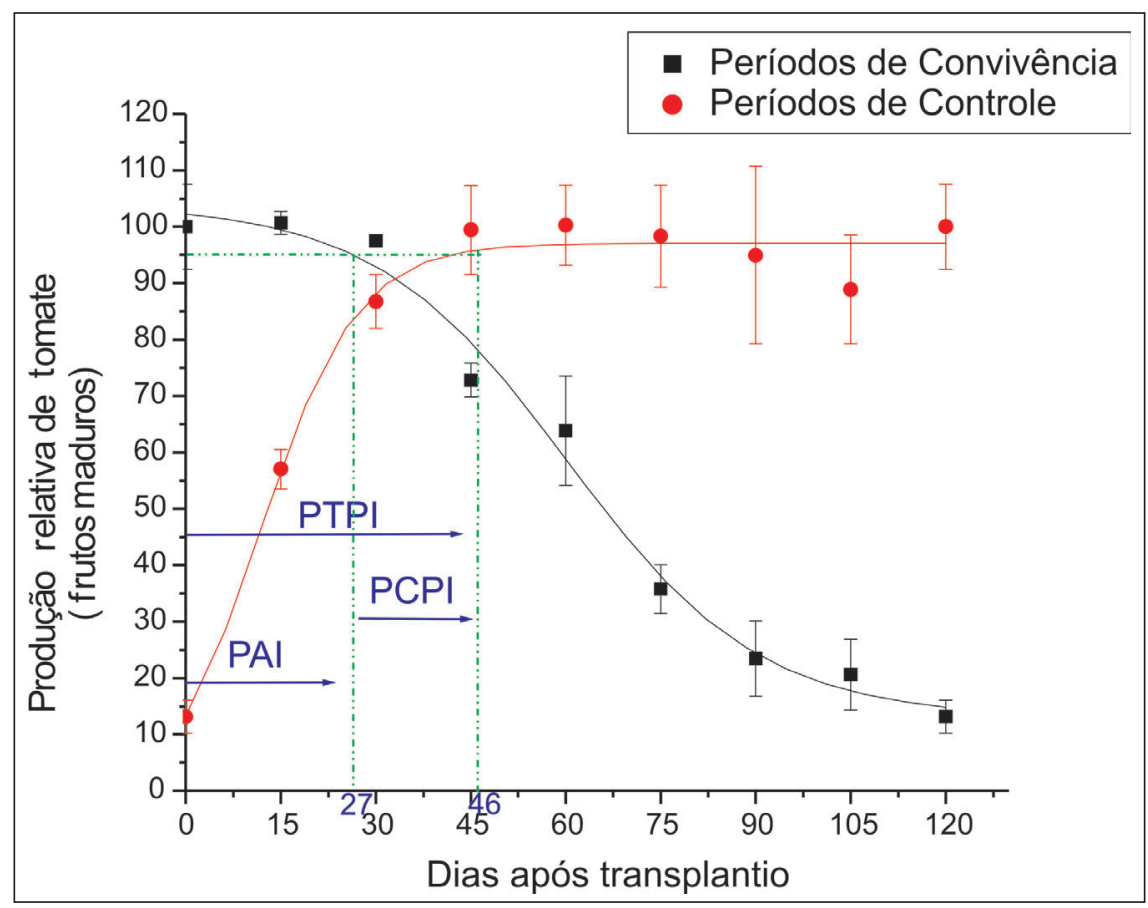

Figura 3. Produtividade relativa de frutos maduros de tomate em função dos períodos com controle ou com convivência com maria-pretinha (Relative yield of ripe tomato as affected by the control or the coexistence with nightshade). PAI - período anterior à interferência (period before interference); PTPI - período total de prevenção à interferência (total period for preventing interference); PCPI - período crítico de prevenção à interferência (critical period for preventing interference). Goiânia, UNESP-FCAV/Unilever, 2003.

ríodo total de prevenção à interferência - PTPI) (Figura 3). Assim, o controle das plantas de maria-pretinha foi crítico no período compreendido entre 27 e 46 dias após o transplantio (período crítico de prevenção da interferência PCPI) (Figura 3). Bucklew et al. (2006), estudando a interferência de Solanum ptycanthum sobre o tomateiro, observaram que a produtividade da cultura diminuía à medida que a convivência com a planta daninha era maior. Concluíram ainda que no período compreendido entre 28 e 50 dias após o transplantio não deveria haver convivência entre as duas espécies para que as perdas de produtividade da cultura não ultrapassassem $20 \%$. Nascente et al. (2004) determinaram que o período crítico de infestação de uma comunidade de plantas daninhas sobre plantas de tomate, cultivar IPA-5, se dava entre o $33^{\circ}$ e 76 o.dias após a implantação da cultura.

Estimou-se os valores do limite superior do PAI e do PTPI em função da tolerância de redução de 2,5; 5 e 7,5\% na produtividade de frutos maduros do tomateiro. Tolerando-se $7,5 \%$ de redu- ção na produtividade, o PAI foi de zero a 30 dias após o transplantio (DAT) e o PTPI foi de zero a 36 DAT. Reduzindose os níveis de tolerância para 2,5\%, o PAI passou para 24 DAT e o PTPI para 53 DAT. Aceitando-se que a redução na produtividade de frutos maduros de tomate passasse de 2,5 para $7,5 \%$ podem ser acrescentados seis dias no período de convivência. Por outro lado, para aumentar a produtividade de 92,5 para $97,5 \%$, foi necessário um acréscimo de 17 dias no período de controle. Isto mostra o quão agressiva é a maria-pretinha sobre o tomateiro, principalmente sobre sua produtividade final.

Nas situações em que o PCPI é muito longo, a principal medida de controle para minimizar as perdas de produtividade é a utilização de herbicidas aplicados em área total, uma vez que o controle mecânico exigiria elevada frequência de operações, o que aumentaria o custo de produção, além de, no caso do tomate industrial, aumentar os riscos da infecção por doenças bacterianas. $\mathrm{O}$ controle da maria-pretinha deve ser realizado no momento correto, ou seja, o mais próxi- 
mo possível do PAI. O controle antecipado acarretaria em um PCPI maior, o que implicaria em maiores quantidades de operações de controle, ou seja, maiores custos de produção. $\mathrm{O}$ controle atrasado provocaria redução de produtividade, além do que propiciaria um aumento no ciclo da cultura, com conseqüente heterogeneidade de maturação de frutos.

\section{REFERÊNCIAS}

AGRIANUAL. 2005. Anuário da agricultura brasileira. São Paulo: FNP Consultoria. p.495-501.

BLANCO HG. 1972. A importância dos estudos ecológicos nos programas de controle de plantas daninhas. Biológico 38: 343-350.

BLEASDALE JKA. 1960. Studies on plant competition. In: HARPER JL. (eds). The biology of weeds. Oxford: Blackweel Scientific Publications. p.133-142.
BUCKLEW JK; MONKS DW; JENNINGS KM; HOYT GD; WALLS RF. 2006. Eastern black nightshade (Solanum ptycanthum) reproduction and interference in transplanted plasticulture tomato. Weed Science 54: 490495.

CLARK GL. 1971. Elementos de ecologia. Barcelona: Omega. 534 p.

HERNANDEZ DD; ALVES PLCA; SALGADO TP. Efeito da densidade e proporção de plantas de tomate industrial e de maria-pretinha em competição. Planta Daninha 20: 229-236.

KOZLOWSKI LA; RONZELLI JÚNIOR P; PURISSIMO C; DAROS E; KOEHLER HS. 2002. Período crítico de interferência das plantas daninhas na cultura do feijoeiro-comum em sistema de semeadura direta. Planta Daninha 20: 213-220.

KUVA MA; GRAVENA R; PITELLI RA; CHRISTOFFOLETI PJ; ALVES PLCA. 2001. Períodos de interferência das plantas daninhas na cultura da cana-de-açúcar. II - capimbraquiária (Brachiaria decumbens). Planta Daninha 19: 323-330.
MATTEUCCI SD; COLMA A. 1982. Metodologia para el estudio de la vegetacion. Washington: OEA. 168p.

NASCENTE AS; PEREIRA W; MEDEIROS MA. 2004. Interferência das plantas daninhas na cultura do tomate para processamento. Horticultura Brasileira 22: 602-606.

PITELLI RA. 1985. Interferência de plantas daninhas em culturas agrícolas. Informe Agropecuário 11: 16-27.

SALGADO TP; ALVES PLCA; MATTOS ED; MARTINS JF; HERNANDEZ DD. 2002. Períodos de interferência das plantas daninhas na cultura do algodoeiro (Gossypium hirsutum). Planta Daninha 20: 373-379.

SOARES DJ; PITELLI RA; BRAZ LT; GRAVENA R; TOLEDO REB. 2003. Períodos de interferência das plantas daninhas na cultura de cebola (Allium cepa) transplantada. Planta Daninha 21: 387-396. 